Open Access

\title{
Reconstructing the concept of face in cultural sociology: in Goffman's footsteps, following the Chinese case
}

Xiaoying Qi(D)

\author{
Correspondence: \\ Xiaoying.Qi@acu.edu.au \\ Australian Catholic University, \\ Australia and Hong Kong Baptist \\ University, Hong Kong, Special \\ Administrative Region of China
}

\begin{abstract}
Few readers notice that in a celebrated essay, Goffman, in a footnote, acknowledges the Chinese source of his concept of face. Around the time that Goffman published "On Face-work," Merton urged that theory development requires, among other things, clarification or refinement of concepts. If culture is taken to be effectively related to action and meaning, it is necessary to go beyond the approach in which theories, concepts, and methods developed in one socio-cultural context are simply applied to data generated in another. The present paper shows that concepts from other cultures may challenge taken-for-granted assumptions, received wisdoms, and established conventions. The paper draws on semi-structured interviews with respondents in a number of sites in mainland China. Examination of the various notions of face articulated by respondents suggests possible developments in sociological conceptualizations of face neglected in previous discussion. It is shown that an individual's face generation and outcome may arise out of another individual's status or behavior. An individual's action may give rise to a collective face outcome and a collective's circumstances may have impact on an individual's face state. Additionally, it is shown that face itself may become an object of self-conscious deliberation and construction. The paper demonstrates that conceptualizations employed by Chinese subjects can lead to the identification or illumination of properties and relations neglected in mainstream cultural sociology. New directions of research and theorization are thus encouraged by incorporation of culturally extraneous experiences and categories into mainstream sociology.
\end{abstract}

Keywords: Face, Concepts, Identity, Chinese culture, Intellectual entrepreneur, Theory development

\section{Introduction}

An assumption underlying this paper is that global asymmetrical knowledge flows operate in which theories, concepts, and methodologies that are developed and employed by social and cultural researchers in North America and Western Europe are disseminated to other places (Qi 2014). A major challenge to the development of a global sociology, then, is the persistence of spaces of influence in which the privileges of dominant geo-political powers operate in intellectual production, including sociological formations (Bhambra 2007; Bhambra 2014; Connell 2007; Go 2016; Jacobs and Townsley 2008; Rodríguez et al. 2010). If culture is taken to be effectively related to action and

(c) The Author(s). 2018 Open Access This article is distributed under the terms of the Creative Commons Attribution 4.0 International License (http://creativecommons.org/licenses/by/4.0/), which permits unrestricted use, distribution, and reproduction in any medium, provided you give appropriate credit to the original author(s) and the source, provide a link to the Creative Commons license, and indicate if changes were made. 
meaning, it is necessary to go beyond the assumption that theories, concepts, and methods developed in one socio-cultural context can be meaningfully applied to data generated in another. This proposition challenges the practices in which North American and European theories and concepts are simply applied to extraneous cases. Such situations have been described as either exploitative, with the "exotic" case simply mined for data, or, possibly more seriously, it is seen as generative of flawed description or theory (Hamilton 2006, pp. 50-74, pp. 220-236). Lamont's (2000, p. 606) comment on the sociology of knowledge and science is applicable here, that "the rise of one distinctive worldview through social science discourse cannot account for the diversity of human orientations and experiences". Underlying the argument of the present paper, then, is an acknowledgment that development of social sciences "on a world scale" is hampered when the mobility of theoretical concepts from one cultural setting to another reflects geo-political dominance rather than intellectual suitability.

The situation outlined in the above paragraph, and alternatives to it, can be simply characterized. In a previous empirical study of the treatment of the Chinese concept of guanxi in social science and management theory, it was shown that there are three possible forms of relations between the concept of guanxi and the theory applied to it (Qi 2012). One possibility is that guanxi is "explained" through application of a pregiven or mainstream theory insofar as the concept refers to a particular subject matter which is dealt with by the theory in question. In this case, the concept affects the structure of the theory and its explanations in the most limited sense, only insofar as it is necessary for the theory in question to specify a subject matter. A second possibility is that a concept is seen as "rounding out" or providing a new perspective on the theory applied to it. In this sense, the concept in question may be said to contribute to the development of the theory that incorporates it or at least key aspects of the relations or factors it refers to. An instance of this situation is the way in which Lin (2001), in drawing on an analysis of guanxi, made a contribution to the theory of social capital by distinguishing between social capital that occurs at the interpersonal level and social capital that arises at the societal level (see also Qi 2013a). A third possibility is that aspects of guanxi are applied to existing theoretical concerns in a way that transforms the standard theory. The application of the concept of guanxi as a distinctive form of information codification and diffusion led Boisot and Child (1996) to develop a theory of industrial governance and transaction as a social form they called "network capitalism". In this instance, the Chinese concept guanxi is incorporated into the interior of the theory and thereby generates a transformation of existing theory in a way that may not otherwise occur. This latter instance can be regarded as knowledge flow from the periphery to the core. The three possibilities outlined here are summarized in Table 1.

The argument here acknowledges the consequences of geo-political dominance for knowledge dissemination but shows that concepts drawn from extraneous knowledge systems may both challenge and also be integrated into mainstream social and cultural theories, in order to enhance their competence by directly addressing prevailing assumptions and approaches. The present paper shows how concepts drawn from Chinese practices of face may challenge taken-for-granted assumptions of mainstream cultural sociology, its received wisdoms and established conventions. In doing so, it demonstrates that mainstream social and cultural theory can be improved through a 
Table 1 Knowledge flow and theory development

\begin{tabular}{llll}
\hline $\begin{array}{l}\text { Direction of knowledge flow } \\
{[\mathrm{M}=\text { Metropole; }} \\
\mathrm{P}=\text { Periphery }]\end{array}$ & Concept-theory relation & Place of guanxi in the theory & $\begin{array}{l}\text { Scope of the concept } \\
\text { of guanxi }\end{array}$ \\
\hline $\mathrm{M} \rightarrow \mathrm{P}$ & External & $\begin{array}{l}\text { Object of explanation } \\
\text { (explanandum) }\end{array}$ & Local relevance only \\
$\mathrm{M} \leftrightarrow \mathrm{P}$ & Internal (nondirecting) & $\begin{array}{l}\text { Secondary explanatory } \\
\text { concept (explanans) }\end{array}$ & Partial general relevance \\
$\mathrm{M} \leftarrow P$ & Internal (directing) & $\begin{array}{l}\text { Primary explanatory } \\
\text { concept (explanans) }\end{array}$ & General relevance \\
\hline
\end{tabular}

transforming encounter with the Chinese concepts in question, which through their incorporation modify and change the extant theory of face.

A focus on concepts, concept formation and refinement is central in the argument to follow. In his classic discussion of the reciprocal relationship between sociological theory and empirical research, Merton (1968, p. 169) notes that the "basic requirement of research is that the concepts, the variables, be defined with a sufficient clarity to enable the research to proceed". Merton (1968, pp. 143-145) indicates that concepts are the means through which observations are formed and orientated and that their significance in identifying and defining the elements of empirical data and their relationships is therefore fundamental. The task of conceptual analysis, refinement and innovation or development is necessary to identify and understand previously neglected objects and relationships and thereby advance social theory. In this way, a change of concepts, or an introduction of new ones, is a change of theory (Merton 1968, pp. 146-147). Because concepts are the elements from which theories are constituted, it is possible to contribute much to our understanding of sociological theory and theory change by concentrating on concepts. Conceptual innovation and refinement invigorates theories, and enhances their competence and capacity for explaining social and cultural phenomenon, relationships and characteristics, and therefore our understanding of those things.

As the sub-title of this paper indicates, the purpose here is to extend an important but neglected aspect of the strategy engaged by Goffman in generation of his classic discussion of face. The concept of face refers to a social representation of a person reflecting the respect, regard or confidence others have in them which the person in question is conscious or aware of himself or herself (Goffman 1972, p. 5). Face is thus a self-image a person forms in terms of their being positively or negatively regarded by others. In his path-breaking treatment of "face" and "face-work", Goffman (1972, pp. 5-6) draws upon and acknowledges his debt to the concept of mianzi (face). While experience of face is arguably general, in the sense that in all cultures a person's self-image is formed intersubjectively in reflection of the assessments of others, the high salience of face in Chinese society means that Chinese experiences and conceptualizations of face highlight aspects of it that are less visible in non-Chinese societies and in existing sociological accounts of the phenomenon, at least up to the time of Goffman's writing. Chinese experiences and understandings of "face" shall be discussed here to show that it is still possible to amplify the current mainstream sociological appreciations and understandings of face by indicating that continuing research on Chinese face reveals characteristics of face otherwise neglected in mainstream cultural sociology. The present paper draws on data from an ongoing study of changes in the social bases and forms of family relations in mainland China, for which semi-structured interviews have been conducted. 


\section{Method}

Data presented below was collected for a larger study concerning changes in the social bases and forms of family relations in mainland China. Qualitative methods are particularly useful in identifying the complexities not only of changing family relationships but also of face phenomena and the dynamic contexts in which they are located. Such approaches in general terms refine existing theoretical perspectives (Layder 2005, p. 20; Merton 1968, pp. 156-171). In this way, the ground is prepared for an empirically based and theoretically informed examination of face in mainland China during the current period of market reform.

The larger study referred to in the above paragraph draws on 154 semi-structured indepth interviews conducted in the cities of Beijing, Changshu, Dongguan, Guangzhou, Hefei, Shanghai and Shenzhen from 2015 to 2017. Interviews were conducted with three distinct groups, namely young unmarried people aged between 17 and 29 years, adult children who are themselves parents aged between 28 and 48 years, and elderly respondents aged between 50 to 80 years. Persons in the sample currently or previously employed include individuals in both blue-collar (45) and white-collar categories (68). The interview samples include both men (69) and women (85). Interviews lasted approximately 2 hours although some were longer, the longest being three and a half hours.

The data was sorted and coded according to thematic constructions. Multiple readings of transcripts were initially engaged to derive general themes. Each transcript was then read and coded for indicators of themes. These themes were labeled and organized in terms of the connections between them. Clusters of themes were then organized to create higher-order concepts. Data is coded in terms of name, age, sex, education, employment, income, village/town/city origin, as well as a number of themes associated with relocation strategy, family responsibilities, relational practices and patterns, health status and other issues that are not relevant to the present paper. The final stage of coding focused on hypothesizing for theoretical development. For the purposes of the present paper, the data was re-examined in order to locate face-related references provided by respondents.

\section{Face and its others}

Although research concerning "face" as a specific theme of investigation may not have broad application in mainstream sociology, with the exception of Goffman and those who operate within his framework, a broader concept of face, referring to the social anchoring of self in the gaze of others, is more generally seen to have a wider appreciation in general sociology and is represented in an historically enduring and significant discussion. The eighteenth-century Scottish thinker Adam Smith captures the details of the relationships underlying face when he describes what he calls the "looking-glass" self:

We suppose ourselves the spectators of our own behavior, and endeavor to imagine what effect it would, in this light, produce upon us. This is the only looking-glass by which we can, in some measure, with the eyes of other people, scrutinize the propriety of our own conduct. If in this view it pleases us, we are tolerably satisfied... if we are doubtful about it, we are often, upon that very account, more anxious to gain their approbation, and ... we are altogether distracted at the thoughts of their censure, which then strikes us with double severity (Smith 1982, p. 109). 
By imagining how they are seen by others, individuals can then evaluate their own behavior; thus, a self-image generated in relations with others reflexively leads individuals to behave in a socially approved manner, according to Smith.

Even in individualistic cultures, cultures in which persons believe themselves to be self-sufficient and autonomous, where awareness of their dependence on the opinion of others may be relatively absent, persons are nevertheless subject to the imperatives of face in the sense indicated above. Certainly, this is the view of Charles Horton Cooley, who followed Smith's terminology and is widely credited with introducing the notion of the looking-glass self into modern sociology. He wrote:

Many people ... will deny, perhaps with indignation, that ... care [of what others think of them] is an important factor in what they are and do. But this is illusion. If failure or disgrace arrives, if one suddenly finds that the faces of men show coldness or contempt instead of the kindness and deference that he is used to, he will perceive from the shock, the fear, the sense of being outcast and helpless, that he was living in the minds of others without knowing it, just as we daily walk the solid ground without thinking how it bears us up (Cooley 1964, p. 208).

This "outgoing of the imagination towards another person's point of view", Cooley (1964, p. 206) observes, "means that we are undergoing his influence". According to this argument, then, the individual is connected with others through face, in which the subjectivity of self is never autonomous but derived from a prior trans-subjectivity of inter-relations between persons.

The trans-cultural significance of face is acknowledged by Goffman (1972, p. 44) when he refers to the fact that "underneath their differences in culture, people everywhere are the same ... [in the sense that one] is taught to be perceptive, to have feelings attached to self and a self expressed through face, to have pride, honour, and dignity, to have considerateness, to have tact and a certain amount of poise". Through their social relationships, individuals seek the approval or respect of others and typically desire to achieve a position of approbation in the social group to which they belong. Not only is face thus experienced in all human societies, but within any one of them it operates very broadly indeed. David Ho (1976, p. 883) argues similarly when he claims that face should be regarded as a concept of central importance in sociology "because of the pervasiveness with which it asserts its influence in social intercourse, it is virtually impossible to think of a facet of social life to which the question of face is irrelevant". The consensus of a number of writers, from a broad social science background, is that face includes a socially formed self-image that is essential to the dynamics of an individual's relations with others irrespective of their cultural background or national context. The qualification, that while face itself may be trans-culturally pervasive, features important to it in any particular culture may not be general across them all (Ho 1976, pp. 881-82), is an additional prime element of face that will be drawn upon in this paper for purposes of conceptual refinement.

I first began exploring Chinese conceptualizations of face and their usefulness in expanding Goffman's approach to face in an earlier paper (Qi 2011). In that paper, I observed in a footnote that while face (mianzi) is important to Chinese social relations, there are surprisingly few scholarly discussions of face in Chinese sources. Only recently 
has the concept of face gained attention from scholars writing in Chinese in fields including sociology, psychology and management. The classic reference to Chinese face is not Confucius or the more recent Chinese sociologist Fei Xiaotong but an American missionary, Arthur Smith (1845-1932), who spent 54 years in China and wrote books introducing China to interested non-Chinese readers. In Chinese Characteristics, first published in 1894, Smith wrote on a number of topics, including the physical vitality of the Chinese, on filial piety, mutual suspicion, and other themes he regarded as quintessentially Chinese. The first chapter of Chinese Characteristics, though, is devoted to face. Smith (1894, p. 17) says that face is "in itself a key to the combination lock of many of the most important characteristics of the Chinese". While Smith's writings aroused the interest of foreigners regarding the importance of face in China-Smith was "responsible for the introduction of the notion of 'losing face' into English" (Kipnis 1995, p. 120)-his discussion even more surprisingly awoke at the time a Chinese awareness of the omnipresence and significance of face in Chinese culture.

One of China's most influential writers and cultural critics of the early twentieth century, Lu Xun, read Chinese translations of Arthur Smith and was impressed by his insightful observations concerning Chinese character. Inspired by and in reference to Smith, Lu Xun wrote a short essay on face which was published in the magazine Manhua Shenghuo (Caricature of Life) in 1934. Lu Xun writes:

The term "face" keeps cropping up in our conversation, and it seems to be such a simple expression that I doubt whether many people give it much thought. Recently, however, we have heard this word on the lips of foreigners too, who seem to be studying it. They find it extremely hard to understand, but believe that "face" is the key to the Chinese spirit and that grasping it will be like grabbing a queue twentyfour years ago [when wearing a queue or pig-tail was compulsory] - everything else will follow (Lu 1960, p. 129).

Another influential Chinese writer and social and cultural critic, Lin Yutang, also wrote about face but his writing was directed toward an American not a Chinese audience. Lin lived most of his adult life in the USA. His book My Country and My People (1977) is written in English and aims to introduce China and Chinese culture and social mores to American readers. In the book, Lin (1977, pp.186-93) discusses face. Face, he says together with fate and favor are "three sisters [who] have always ruled China, and are ruling China still" (Lin 1977, p. 186). Lin places face before fate and favor to emphasize that "[i]t is more powerful than fate and favour, and more respected than the constitution" (Lin 1977, p. 191).

There can be no doubt that face is central to Chinese culture and it is sometimes supposed that face is so significant in the behavior of Chinese people that paradoxically it is taken for granted by them. But this in itself cannot adequately explain the absence among Chinese scholars of studies concerning face. Part of the explanation must take note of the manner of the introduction, establishment and development of sociology in China. This constitutes an instance of knowledge flow in which existing native Chinese concepts were largely ignored and a set of foreign theories was simply applied to an alien or exotic context. Sociology as an intellectual and cultural artifact originating in America and Europe was first introduced into China in the early twentieth century by 
American missionary sociologists (King and Wang 1978, p. 42; Wong 1979, pp. 11-19). Indeed, during this early formative period, between 1910 and 1930, the discipline of sociology in China consisted of "such distinct foreign and religious features", as Siu-lun Wong (1979, p. 11) put it, "that it might be named American missionary sociology". Even when Chinese non-missionary universities offered courses in and established departments of sociology, they were "closely connected with American interests and heavily influenced by American sociology" (Cheng and So 1983, p. 473). Prior to 1916, most sociology lecturers in Chinese universities were foreigners and the majority of them were Americans ( $\mathrm{Li}$ et al. 1987, p. 617). Theories, concepts and methods developed in the USA and Europe and reported in textbooks principally published for American college courses were used, and American teaching and research interests were pursued in sociological study in China, but not of China. In this context, in which the teaching of and research in sociology was through imported American textbooks and by largely American missionary teachers, the means for apprehending characteristically Chinese cultural properties, such as face, were simply absent.

As sociology underwent sinicization, during the period from 1930 to 1949, the concept of face was again neglected as a subject warranting serious sociological research or commentary. During this period, sociology was concerned with practical problems of agrarian inequality and poverty and therefore directed to "solve social problems through reformism and social adjustments" (Cheng and So 1983, p. 475). The fate of Chinese sociology changed dramatically after the foundation of the People's Republic in 1949 with the victory of the Chinese Communist Party. From this time, sociology was compelled to adopt Marxist-Leninist principles and the role of sociology was, according to an official statement, to "learn to use Marxism-Leninism and the thought of Mao Tse-tung to analyze concretely practical social situations" (quoted in Skinner 1951, p. 369). The areas of research for sociologists at this time were more or less confined to class structure and land ownership, studied through the lens of Marxist materialist terminology (Cheng and So 1983, p. 478). Under such political and social conditions, possibilities of research on concepts such as face were again absent. In 1952, all university departments in China of sociology, political science and also law were abolished (King and Wang 1978, p. 49). It was not until 1979, when China "opened its door" to the rest of the world, that sociology was re-established as a discipline to be taught in universities and to be the intellectual basis of empirical and theoretical research. In each phase of its development in China, up until the present time, sociology simply ignored the concept and practice of face, for quite different reasons but with the same effect.

In recent times, attempts to explain Chinese social practices to foreign social scientists have for the first time made face a theme for research and systematic study by Chinese social scientists. The discussion of face by Chinese sociologists, beginning with Hsien Chin $\mathrm{Hu}$ (1944), whose work is drawn upon and acknowledged by Goffman, and later including David Ho (1976), Chuansi Stephen Hsu (1996), Kwang-kuo Hwang (1987a) and Wenshan Jia (2001), is motivated at least in part to explain Chinese social practices to non-Chinese audiences and is written in English. More recently, however, there has risen not only in mainland China but also in Taiwan an interest among Chinese-language social scientists to compare Chinese and non-Chinese societies. In this context, face has become a topic about which there is now Chinese-language 
discussion among Chinese sociologists and social psychologists (Hwang 1987b; Lu 1996; Zhai 1994, 1995, 2006). The growing scholarly and research interest in face in China has meant that Ho was encouraged to later publish a Chinese version of his (1976) paper in a book (Ho et al. 2006), and similarly, Kwang-kuo Hwang's (1987a) paper was simultaneously published in Chinese (Hwang 1987b).

When we think of Chinese sociology today, the hallmark event was the re-introduction of sociology into Chinese universities from 1979. Associated with this process is the significant number of sociology students who studied abroad and took PhDs from predominantly American and European universities and returned to China to teach and conduct sociological research. In consideration of the treatment of face, though, it is important to remember those Chinese sociologists who from the 1940s worked in American universities (Hu 1944; Ho 1976; Hsu 1996) but nevertheless wrote on Chinese themes. This aspect of "Chinese sociology" is one in which its practitioners are concerned not simply to apply alien sociological concepts to questions concerning the analysis of Chinese culture but to introduce Chinese concepts, in this case the concept of face, to English-language sociology sources.

\section{An individual's face in relation to another}

Face is a self-image a person forms in terms of their interest in being favorably or appropriately regarded or judged by others. It is a social representation of a person reflecting the respect, regard or confidence others have in them which they both possess or are consciousness of themselves and of which others are aware (Goffman 1972, p. 5; Qi 2011, p. 287). The evaluations of self which are constitutive of a face-state are thus necessarily socially current and never merely personal or idiosyncratic. It is often noticed that in societies influenced by Protestant culture, individuals are presumed to be autonomous and to behave on the basis of decisions determined by their individual will (Hamilton \& Wang, 1992, pp. 25-26). In these societies, individual autonomy is mediated primarily by subjection to a providential God, at least until the late eighteenth century, or since that time through the rule of law and related abstract rational constructions. Individual autonomy in these societies is limited by individual rights, religious or legal, which specify its basis and scope. In this context, an individual's facestate is assumed to depend on how they represent themselves or behave in a way that produces social acceptance or respect. In Chinese society, on the other hand, individuals are embedded in social relationships in which there are obligations defined by the roles through which social engagements occur. This entails that a person's face-state shall depend not only on their own behavior but also on the behavior of other persons with whom they are socially connected. This entails another side of face, in which a person's face is also a consequence of the behavior of face-related persons. Such facerelated persons may include family members, but also persons in teacher-student, employer-employee and other individual-group relationships. This issue is more or less ignored in the literature on face, but has relevance for a comprehensive understanding of face. Conceptualization of it can help fill gaps left by the current conventional theorization of face.

In his classic statement of face, Goffman (1972, p. 5) reserves the notion of face to indicate only a person's self-image in terms of how the person in question is regarded by others: "The term face may be defined as the positive social value a person effectively 
claims for himself by the line others assume he has taken during a particular contact". From this perspective, a person's face-state derives only from their own behavior and how that behavior is regarded by others. But as face is crucial to a person's relations with others, so it is that an individual shall be concerned not only with their own behavior in consideration of their face but also the behavior of others who they believe may affect the formation of their own face-state. This type of situation is revealed in many of my fieldwork interviews, in which a concern is reported that an individual's own face-state is affected by the behavior of another individual. Of the numerous examples to be found in my interview transcripts, three shall be reported here.

The first is the report of an individual's behavior that arose out of a concern for another's face state which in turn had consequences for their own face state. Ming reported that as a result of declining to join colleagues of his girlfriend to a gathering in a karaoke bar, Ming became worried that his behavior would lead to his girlfriend's loss of face. He remarked:

What could I do to make up her face? I thought of the idea of treating her colleagues with a free meal. I took a huge box of Kentucky chicken, a pack of zhouhei duck and two boxes of biscuits to her workplace for her colleagues to share. Wanquan shi weile gei ta cheng mianzi; Zhexie qian wo wanquan buyong huade (I did this simply to gain her face; otherwise I don't need to spend the money at all).

According to the Chinese norms of interpersonal behavior (renqing), an invitation to Ming from his girlfriends' colleagues indicates their recognition and acknowledgement of him, and through this, they effectively give him face. In terms of these norms, Ming's acceptance of their invitation would indicate his return of face to them. By declining this invitation, not only Ming's face but also his girlfriend's face is in jeopardy. Ming's strategy of providing his girlfriend's colleagues with a meal in their work-place is a display of renqing on his part that is designed to restore his girlfriend's face in the eyes of her colleagues and, incidentally, it has the consequence of regaining with them his own lost face.

A second example of an individual's face in relation to another operates in the context of match-making (xiangqin). Many of my young female respondents, including university graduates, indicated that they felt very embarrassed by their parents' attempts to make xiangqin arrangements. These arrangements typically involve a meal at which the two young people as well as both sets of parents are present. Lanlan (24 year-old, master's degree holder) told me that her mother continuously urged her father to introduce a most suitable young man to Lanlan. Due to her mother's perseverance, Lanlan's father eventually did arrange xiangqin for her, but it did not go according to her mother's expectations:

Coincidently my mother disliked the young man very much. I didn't like such a situation, meeting a stranger in such a way. I didn't have feelings for that young man. However, wo ma de lian baide tai nankan le (My mother's face was displayed so "ugly", very obviously showing her dislike of the young man). I know that my father is concerned with face so instead of showing my true feelings about that young man I talked very pleasantly with him and his parents. 
A few days later, Lanlan had coffee with her father and the xiangqin event was discussed. Lanlan recalled that her father said:

They came so far away to see us and meet you. Ni mama nayang zhen rangren mei mianzi (Your mother's behaviour led to our face loss). If I didn't behave warmly toward them, they would probably leave without finishing the meal. Ruguo nayang de hua, tai mianzi gua buzhu le (If that happened, our face wouldn't be maintained).

The fact that the young man's parents' came from another city to meet Lanlan and Lanlan's parents was regarded as providing face to Lanlan's parents. In terms of renqing etiquette, Lanlan's family should have responded with warmth in order to return face. The display of a "dirty" face by Lanlan's mother disrupted both the renqing norm and the provision of reciprocal face, which in turn potentially could have entailed face loss for Lanlan's father. In order not to doubly jeopardize her father's face, Lanlan behaved in an outgoing and pleasant manner to the young man and also to his parents. The possibility that the young man's family might terminate the meal and depart early was thus prevented and the prospect of Lanlan's father's face loss was averted. It can be seen from this account that Lanlan's father's face state and its prospective decline is not only an outcome of his own behavior but is contingent on his wife's behavior and also his daughter's behavior.

Finally, the case of an even more complex causal transition and participation of others in face state is related by another informant. Gang (22-year old, male, university student) reported:

My mother has become much happier since my admission to this university. The university at which I am studying has a relatively good ranking. It is internationalized with good academic reputation and teaching resources. ... Not only my image in my mother's eyes has changed but also her relationship with my father has improved. After my father went bankrupt a number of years ago my mother hadn't been able to look up at others and she quarreled a lot with my father. My mother feels that she has gained enormous face through my going to university.

The face transitions in this statement are numerous. Gang's father's change of status from a successful business man to a failure led to loss of face for Gang's mother. She found it hard to face her relative, friends and colleagues. Her face standing is also redeemed through a third person, Gang. The regaining of face through her son's enrolment in a good university leads Gang's mother to also change her relationship with her husband. Gang's mother's face gain through her son's change of circumstance and the face relations between her and her husband point to a complexity of experience of face and its causation that is overlooked in standard mainstream accounts of face.

The data presented in these three cases run against one aspect of the current sociological understanding of face. The complex bases of an individual's face state and the responsibility of another person's behavior in relation to a particular individual's face state is outside of the scope of the conceptualization of face in Goffman's account of face. In light of the difference between cultural suppositions underlying the notion of face, it is important to notice the possibility in any cultural setting of a person being embarrassed 
by the behavior of another person with whom they are in some way connected or associated. That is, it seems to be a wide-spread and not a culturally limited experience that one can lose face through the behavior of another. A gain of face may similarly arise. In Europe or America, a daughter would feel embarrassed, lose face, if her mother jumped a queue. Similarly, it is not unusual for an American, Australian or British student to take pride, gain face, by having an eminent scholar as their supervisor. Studies of face typically understand the social production of the face state of an individual only in relation to the individual's own behavior and how that behavior is regarded by others. Nevertheless, as indicated above, there is a further dimension of face in which an individual's face is a consequence of the behavior of face-related others.

\section{An individual in relation to collective face and a collective in relation to individual face}

An individual's behavior or change of status may lead to a change of face not only of another individual but of a group, including a nation. A number of my university student respondents had experienced study exchange. They typically indicated that they became more conscious of themselves as Chinese when they were overseas. A common expression that they related to me is "Wo buneng gei zhongguo ren qiulian", literally "I cannot lose Chinese people's face". Another remark often shared among these students: "Wo xiwang zhongguo qiangda. Wo zuowei zhongguo ren ye you mianzi", which means "If China is strong, then I gain face as a Chinese".

The formation of a face-state in these cases derives from the relation between an individual and a collective, and it may run in both directions. When an individual feels that their circumstances will lead them to be seen as a representative of a group to which they belong, then their behavior may impact on the face of others who are seen to belong to the same group. Again, this is a general not a Chinese experience although perhaps only in Chinese culture is there a recognizable concept that captures the experience. A Danish woman in Australia is aware of another Danish woman behaving badly. She does not know the other woman and is not responsible for her behavior, but she cannot help feeling embarrassed or ashamed, as a Dane, because of what the other woman has done. It is also commonplace for persons to experience a change of face because of the behavior of their nation or its formal representatives. Since the election of Donald Trump as US President, it is frequently remarked by Americans that they are embarrassed to be American. As indicated above, studies of face typically confine themselves to the social production of the face state of an individual in relation only to their own behavior and how it is regarded by others. But, as related here, there is another dimension of face in which an individual's face derives from their relations with collective entities.

\section{Face as a self-conscious project}

The discussion of face in the sociological literature operates on the assumption that face is an outcome of how a person is regarded by others in formation of a self-image that is an unintended consequence of their behavior and circumstance. In a Chinese cultural context, it is recognized that persons may be engaged in the construction of face as a self-conscious project, not only to achieve the pleasure of social approval and avoid the pain of social disapproval or censure, but as part of an engagement in a 
politics of face as an explicit social practice (Qi 2011, p. 292). The claim here is not that this is an exclusively Chinese practice but that the Chinese practice has conceptual capture of relevance for a general theory of face but which is not currently acknowledged in mainstream sociological theory.

There is now a large academic literature on China's internal labor migration, and a significant discussion within that literature concerns the remittances sent home by migrant workers. My fieldwork indicates that a significant portion of the money remitted by rural migrant workers is spent on face-oriented etiquette. Ling's husband became a migrant worker in Shenzhen, a major destination of rural workers, in 2003. At that time, he earned approximately CNY600 per month and remitted CNY500 per month to his wife and children in the village, leaving very little money for himself. When asked how the money was spent, Ling said, "zaijia you shenme chijiu yao songyi a!", meaning "It is a custom to attend banquets and give gifts in the village". Ling reported to me that over $80 \%$ of her husband's remittance was spent on village banquets and gifts and that the remainder was put aside for the educational needs of their two sons. This pattern of expenditure required Ling to often borrow money to satisfy daily needs. Another respondent, Pei, similarly remarked that it was not unusual for her family to not be able to afford meat, but at the same time it was unthinkable to avoid gift-giving in the village and returning renqing. It may not be an exaggeration, therefore, to claim as Zhang and Baker (2008, p. 22) do, that to Chinese people mianzi (face) is "more important than life itself" and that "often mianzi is ranked before their health or wellbeing".

In the cases mentioned above, face is not a residual category of social mechanisms of perception and approval, of self through other's perceptions, either positive or negative; rather, face itself becomes an object of self-conscious strategies. Many rural-to-urban migrant grandparents reported that they spend from CNY6000 to CNY10,000 on renqing rituals during the Chinese New Year when they return to their villages. Yue (55, from Jiangxi) relocated to the city in order to provide childcare for her son and daughter-in-law. She capitalizes on the task of looking after her own grandchild by concurrently providing paid childcare for another young couple. Through paid childminding Yue earns up to CNY1000 a month. She frankly remarked, "Wo zuomeng dou xiang zhuanqian" (I long to make money so much that I even make money in my dreams). When asked why she has such a strong desire to make money, she confided to me: "Wo yao mianzi a!" (I want to gain and maintain face). She continued,

I need money to spend when I return to my home village during the Chinese New

Year. I need to show that I'm doing well in the city. I need to buy milk power and other things for my mother, buy new clothes for my waisun (maternal grandchildren), give my three brothers each CNY700 as they support my mother. I need to visit my relatives and give hongbao (money in red-envelopes). I need to give CNY300 to CNY400 when a child in the village reaches a full one-month. For these things I need to spend CNY6000 to CNY7000 a year.

Yue and the other grandparents I interviewed spend very little money on themselves. One grandmother reported that she regularly walks through four markets, comparing prices, in order to save money. While a necessary underlying aspect of social behavior face may also be a distinct and distinguishable cultural object in which an explicit 
concern for face is itself a factor in motivating the action and influencing the behavior of individuals.

A set of culturally explicit rules operate by which face is understood as a thing that may be achieved, lost and saved and in any event is required to be at least maintained. Nan (53, female, from Hunan) reported that more than CNY60,000 was spent on her mother-in-law's funeral which led to her incurring a debt of CNY20,000. Nan reported:

It lasted 4 days and 3 nights. It includes the payments of banquets, cigarettes, Daoist rituals, and yaogu (waist drum) and lion performance. All the relatives were there eating; all the people from the dui (brigade or squadron) were there eating. More than 40 tables for the first 3 days and 10 tables for the fourth day and each table cost more than CNY400. Yaogu and lion performance cost CNY3000 to 4000.

When asked why so much hard-earned money was spent in this way, and why so much more money was borrowed, Nan replied that it was the local custom to have extravagant funerals and if the custom was not followed her family would be laughed at and lose face.

When face is explicitly recognized as an unavoidable social value and face-work is self-consciously practiced as an activity in its own right, then face becomes more than a dominant expression of social conformity. It ceases to operate as a backgrounded means of intersubjective exchanges between individuals, in which a self-image is reflexively formed through a sense of how a person is perceived by others. It becomes instead an objective of primary concern to all members of a community. In this case, a "display" of banquets and folk performance become required elements of "doing face". Face-focused behavior may affect the well-being of social actors and the interests of those close to them. In these circumstances, a large repertoire of enforcement means emerge in relations between persons. At the same time, conscious and explicit codes of conduct directed to face management emerge that take on enormous social significance. These developments constitute a second order of face when face becomes an explicit and conscious purpose of interaction rather than simply a covert and implicit means of facilitating interaction.

Does a conceptualization of this aspect of Chinese face have broader relevance? In his discussion of the mental life of the metropolis and also fashion, Simmel (1971a, 1971b) points to behaviors of social distinction that are by no means foreign to urban societies in the twenty-first century. Although Simmel does not treat these and associated social practices as instances of face, and Goffmanesque accounts of face fails to assimilate or even refer to such behaviors, a comprehensive conceptualization of face must include them. And yet, it is difficult to find analogies in non-Chinese societies of the types of face maintaining expenditures mentioned above, of returning rural-tourban migrants in China and of the costs incurred for funerals. But such doubt does not bear close scrutiny in light of the following considerations.

\section{The cosmetic face}

It has been reported that women in the USA and also Europe spend almost ten times the amount of money that men spend on appearance enhancing products (Meston and Buss 2009; see also Arnocky et al. 2016; Twigg and Majima 2014). It is widely accepted 
as appropriate that women spend a significant portion of their income on their personal appearance, including purchase of outfits, cosmetics, personal care and possibly some form of medical service ranging from botox treatment to surgical restoration, reconstruction, or alteration of body features, even when they are aware of related health risks (Arnocky and Piché 2014). Consumption in general is acknowledged to have significance for self-identity (Paterson 2006), and status motives have been shown to significantly underlie purchase and consumption of women's cosmetics (Chao and Schor 1998).

Of particular interest in this context are research findings which show that during periods of economic recession women increase their spending on beauty products while decreasing their expenditure on other products (Hill et al. 2012). This tendency to prioritize purchases directed to appearance enhancement over other needs in conditions of resource-scarcity has been explained as a tactic for outcompeting intra-sexual rivals in attracting mates who possess increased resources. This same research shows that higher unemployment is associated with decreased spending on products unrelated to appearance, including furniture, electronics, and leisure or hobby products, and correspondingly associated with increased spending on appearance-related products such as cosmetics and clothing. As unemployment increases, so expenditure increases on products designed to enhance physical appearance.

The behavior described here has an apparently ambiguous relationship with the giftrelated expenditures of Chinese rural-to-urban migrant workers described above. The Chinese expenditure is directed to collective consumption whereas the expenditure and related consumption described in the preceding two paragraphs operates at the individual level. Also, the Chinese case is self-consciously directed to maintaining or enhancing face, whereas purchase of cosmetics and other appearance-enhancing goods and services is directed to achieving an identity of a particular type that enhances the person's competitive appeal to others. Competitive appeal is mentioned here because, as Simmel (1978, pp. 290-91) notes, one objective of competition is to attract the attention of others. The idea of "competitive appeal" is important in this context because even if the evolutionary psychology explanation of spending on beauty products, as a tactic for outcompeting intra-sexual rivals in attracting mates who possess increased resources, is not accepted then a broader notion, encapsulated in Simmel's idea of a need satisfied by fashion for individual differentiation, can be considered. All of this reinforces the idea that beauty expenditure is for the sake of achieving a particular identity. What, if any, is the relationship between identity and face?

Identity is a vexed concept in sociology. The major approaches to identity, namely identity theory and social identity theory, focus respectively on a person's selfcategorization in terms of either the roles they occupy or the groups in which they have membership (Stets and Burke 2000). In these frameworks, the more personal types of identities that people have of themselves remains under-theorized because a person's self-conception never consists only of the roles or group membership in which they participate, as suggested by expenditure on appearance-enhancing products and service. The idea that values, for instance, may constitute the core of personal identity (Hitlin 2003) is not particularly helpful here. Empirical investigation indicates that the relationship between values and behavior is weak and therefore specification of the concept of value for identity is likely to be unsatisfactory (Bardi and Schwartz 2003; Hechter 1992). Another possibility is to relate personal identity with face. 
There is a cultural imperative in US and European-based social theory to think of personal identity in terms of "interior" properties, including values and other imputed bases of individual preference. But as identity in this sense serves not only as a selfconfirming image but is also a self-presenting force, so presentation of an identity will in turn lead to a social evaluation of which the person involved will have selfawareness. Self-awareness of social evaluation, of course, underlies face, so face can be seen to play a significant role in personal identity. The argument here, then, is that similar to the case of Chinese rural-to-urban migrants who strategically maintain face through expenditure on social consumption, the individual consumption of appearance enhancing products and services is expenditure as a means of strategic maintenance of social face through personal identity. An exploration of face in Chinese societies thus identifies aspects of face that are less obvious in non-Chinese societies and absent in existing mainstream sociological accounts of the phenomenon but which nevertheless require, and invite, further theorization of face formation.

\section{Conclusion}

Integration of Chinese concepts into mainstream sociological theory enhances the explanatory powers of the latter and enriches both the breadth and depth of its apprehension of social phenomena. In this way, the theories in question are transformed (Qi 2014, pp. 227). This paper has demonstrated by method and the example of the Chinese concept of face the means through which concepts drawn from Chinese cultural experience can be responsible for a reinvigoration of empirical research and theory construction. The examination of the notion of face in Chinese cultural experiences identifies previously neglected or less discussed dimensions of the mainstream sociological concept of face. An individual's face generation and outcome may arise out of another individual's status or behavior. An individual's action may give rise to a collective face outcome and a collective's circumstances may have impact on an individual's face state. Many face studies have paid attention to the mechanism associated with social approval and disapproval of the thing that gives rise to face or subtracts from it. This paper highlights the fact that face itself may become an object of self-conscious consideration. The range or scope of the theories brought into this endeavor can be amplified and their depth of analysis can be extended, depending on the format of research and exposition and also the intentions of the researcher. Conceptual innovation and refinement invigorate theories and enhance their competence and their capacity for identifying, understanding and explaining social and cultural phenomenon, relationships and characteristics. This paper may serve the purpose of stimulating and encouraging subsequent research that draws on and integrates concepts from other cultures to lead to an improved, refined and reinvigorated approach to sociological analysis of cultural forms.

In conclusion, it is appropriate to identify the mechanisms through which the integration of concepts from one culture to another occurs. The integration of concepts from one culture into another, including the intellectual culture of mainstream sociological and cultural theory, requires the work of what might be described as intellectual entrepreneurship (Qi 2013b). Intellectual entrepreneurship in the present context includes the selection of ideas, notions and concepts from an extraneous culture for integration into standard or mainstream theory. This process includes overcoming the 
resistance of the receiving culture or theory, which may be achieved by a number of strategies of "normalization" that Goffman, for instance, deftly demonstrates in his development of the concept of "face-work". Through the introduction of a "new" concept into a dominant intellectual and cultural context, the original concept loses its "foreign-ness" and the receiving theory is at the same time modified and possibly transformed. In this way, through social agency, cultural borrowing can be achieved. In general terms, intellectual or theoretical and cultural change never occurs through the power of ideas themselves but requires human agency. The identification of the role of intellectual entrepreneurs and the treatment of the processes they initiate has potentially extensive application in understanding social and cultural change through intercultural concept transference (Qi 2014). One instance of this larger process is the role of typically foreign sociologists who introduce new or refine existing concepts in mainstream theory by drawing upon cultural experiences from outside of the range of standard and established disciplinary practices. The example of Chinese experiences of face in expanding and enhancing the competence of the mainstream sociological concept of face has been provided in the present paper as an instance of both a corrective response to asymmetrical knowledge flow and also a demonstration, through this response, of intellectual entrepreneurship.

Funding

UGC ECS 22604117 and HKBU FRG1/16-17/006.

Ethics approval and consent to participate

Human research ethics approval has been granted by the Committee on the Use of Human andAnimal Subjects in Teaching and Research, Hong Kong Baptist University.

Competing interests

The author declares that he/she has no competing interests.

\section{Publisher's Note}

Springer Nature remains neutral with regard to jurisdictional claims in published maps and institutional affiliations.

Received: 1 May 2017 Accepted: 4 December 2017

Published online: 20 December 2017

\section{References}

Arnocky, S., C. Perilloux, J. Cloud, B. Bird, and K. Thomas. 2016. Envy mediates the link between social comparison and appearance enhancement in women. Evolutionary Psychological Science 2: 71-83.

Arnocky, S., and T. Piché. 2014. Cosmetic surgery as intrasexual competition: The mediating role of social comparison. Psychology 5: 1197-1205.

Bardi, A., and S.H. Schwartz. 2003. Values and behavior: Strength and structure of relations. Personality and Social Psychology Bulletin 29 (10): 1207-1220.

Bhambra, G. 2007. Rethinking modernity: Postcolonialism and the sociological imagination. Basingstoke: Palgrave.

Bhambra, G. 2014. Connected sociologies. London: Bloomsbury Academic.

Boisot, M., and J. Child. 1996. From fiefs to clans and network capitalism: Explaining China's emerging economic order. Administrative Science Quarterly. 41 (4): 600-628.

Chao, A., and J. Schor. 1998. Empirical tests of status consumption: Evidence from women's cosmetics. Journal of Economic Psychology 19: 107-131.

Cheng, L., and A. So. 1983. The reestablishment of sociology in the PRC: Toward the sinification of Marxian sociology. Annual Review of Sociology 9: 471-498.

Connell, R. 2007. Southern theory. Sydney: Allen \& Unwin.

Cooley, C.H. 1964. Human nature and the social order. New York: Schocken Books.

Go, J. 2016. Postcolonial thought and social theory. New York: Oxford University Press.

Goffman, E. 1972. On face-work: An analysis of ritual elements in social interaction. In Interaction ritual: Essays on faceto-face behaviour, ed. E. Goffman, 5-46. London: The Penguin Press.

Hamilton, G.G. 2006. Commerce and capitalism in Chinese societies. London: Routledge.

Hamilton, G.G., and Z. Wang. 1992. Introduction. In From the soil: The foundations of Chinese society, ed. X. Fei, 1-34. Berkeley: University of California Press.

Hechter, M. 1992. Should values be written out of the social scientist's lexicon? Sociological Theory 10 (2): 214-230. 
Hill, S.E., C.D. Rodeheffer, V. Griskevicius, K. Durante, and A.E. White. 2012. Boosting beauty in an economic decline: Mating, spending, and the lipstick effect. Journal of Personality and Social Psychology 103 (2): 275-291.

Hitlin, S. 2003. Values as the core of personal identity: Drawing links between two theories of self. Social Psychology Quarterly 66 (2): 118-137.

Ho, D.Y-f. 1976. On the concept of face. American Journal of Sociology 81 (4): 867-884.

Ho, D.Y-f. 2006. Mianzi and houhei [face and thick skinnedness]. In Shidao renxin: Dui zhongguoren xinli de tansuo [the manners and morals of the time and human psychology: An exploration of Chinese psychology], ed. D.Y-f. Ho, S. Peng, and Z. Zhao, 109-129. Hong Kong: Joint Publishing.

Ho, D.Y-f., S. Peng, and Z. Zhao. 2006. Shidao renxin: Dui zhongguoren xinli de tansuo [the manners and morals of the time and human psychology: An exploration of Chinese psychology]. Hong Kong: Joint Publishing.

Hsu, C.S. 1996. "Face": An ethnographic study of Chinese social behaviour. Ann Arbor: University of Michigan Press.

Hu, H.C. 1944. The Chinese concepts of "face". American Anthropologist 46 (1): 45-64.

Hwang, K. 1987a. Face and favor: The Chinese power game. American Journal of Sociology 92 (4): 944-974.

Hwang, K. 1987b. Renqing yu mianzi-Zhonguoren de quanli youxi [favor and face-The Chinese power game]. Taipei: Juliu Books Company.

Jacobs, R., and E. Townsley. 2008. On the communicative geography of global sociology. Canadian Journal of Sociology 33 (3): 497-520.

Jia, W. 2001. The remaking of the Chinese character and identity in the 21st century: The Chinese face practices. Westport, CT: Ablex Publishing.

King, A.Y., and T. Wang. 1978. The development and death of Chinese academic sociology. Modern Asian Studies 12 (1): 37-58. Kipnis, A.B. 1995. Face: An adaptable discourse of social surfaces. Positions 3 (1): 119-148.

Lamont, M. 2000. Meaning-making in cultural sociology: Broadening our agenda. Contemporary Sociology 29 (4): 602-607. Layder, D. 2005. Doing excellent small-scale research. London: Sage.

Li, H., M. Fang, Y. Wang, B. Sun, and W. Qi. 1987. Chinese sociology, 1898-1986. Social Forces 65 (3): 612-640.

Lin, N. 2001. Social capital: A theory of social structure and action. New York: Cambridge University Press.

Lin, Y. 1977. My country and my people. Hong Kong: Heinemann Educational Books.

Lu, H. 1960. On "Face", translated by H. Yang \& G. Yang. In Selected works of Lu Hsun, volume 4, 129-132. Peking: Foreign Language Press.

Lu, Z., ed. 1996. Zhongguoren de chuantong xintai [the traditional psychology of Chinese people]. Hangzhou: Zhejiang People's Press.

Merton, R. 1968. Social theory and social structure. Enlargeded. New York: Free Press.

Meston, C.M., and D.M. Buss. 2009. Why women have sex: The psychology of sex in women's own voices. New York: Times Books. Paterson, M. 2006. Consumption and everyday life. London: Routledge.

Qi, X. 2011. Face: A Chinese concept in a global sociology. Journal of Sociology 47 (3): 279-296.

Qi, X. 2012. A case study of globalized knowledge flow: Guanxi in social science and management theory. International Sociology 27 (6): 707-723.

Qi, X. 2013a. Guanxi, social capital theory and beyond: Toward a globalized social science. British Journal of Sociology 64 (2): $308-324$.

Qi, X. 2013b. Intellectual entrepreneurs and the diffusion of ideas: Two historical cases of knowledge flow. American Journal of Cultural Sociology 1 (3): 346-372.

Qi, X. 2014. Globalized knowledge flows and Chinese social theory. London and New York: Routledge.

Rodríguez, E.G., M. Boatca, and S. Costa, eds. 2010. Decolonizing European sociology: Transdisciplinary approaches. London: Ashgate.

Simmel, G. 1971a. The metropolis and mental life. In Georg Simmel: On individuality and social forms, ed. D.N. Levine, 324-339. Chicago: University of Chicago Press.

Simmel, G. 1971b. Fashion. In Georg Simmel: On individuality and social forms, ed. D.N. Levine, 294-323. Chicago: University of Chicago Press.

Simmel, G. 1978. The philosophy of money. London: Routledge.

Skinner, G.W. 1951. The new sociology in China. Far Eastern Quarterly 10 (4): 365-371.

Smith, A. 1982. The theory of moral sentiments. Oxford: Oxford University Press.

Smith, A.H. 1894. Chinese characteristics. New York: Fleming H. Revell Company.

Stets, J.E., and P.J. Burke. 2000. Identity theory and social identity theory. Social Psychology Quarterly 63 (3): 224-237.

Twigg, J., and S. Majima. 2014. Consumption and the constitution of age: Expenditure patterns on clothing, hair and cosmetics among post-war "baby boomers". Journal of Aging Studies 30: 23-32.

Wong, S. 1979. Sociology and socialism in contemporary China. London: Routledge and Kegan Paul.

Zhai, X. 1994. Mianzi, renging, and guanxi wang [face, favor and guanxi network]. Zhengzhou: Henan People's Press.

Zhai, X. 1995. Zhongguoren de lianmian guan [the Chinese perspective on face]. Taipei: Guiguan Press.

Zhai, X. 2006. Renqing, mianzi yu quanli de zai shengchan [Renqing, mianzi and the reproduction of power]. Beijing: Beijing University Press.

Zhang, H., and G. Baker. 2008. Think like Chinese. Sydney: Federation Press. 